\title{
Spacing of reinforcer delivery and effectiveness of magazine training
}

\author{
HENRY MORLOCK, LEAANNE STUNKEL, and KEITH WALDMAN \\ State University of New York, Plattsburgh, New York
}

\begin{abstract}
In Experiment 1, three groups of rats were given magazine training with either a 30 -sec or a 120 -sec average interval between reinforcers (drops of water). An extinction test indicated that there was little difference in the stimulus control of dipper-approach responses established by the two schedules. In Experiment 2, rats given magazine training with either the 30-sec or the 120 -sec spacing learned to barpress about equally readily. The results question the efficiency of using long intervals between reinforcers in magazine training.
\end{abstract}

Magazine training (MT) involves operating the reinforcer-delivery mechanism in an operant chamber in order to accustom naive subjects to the sounds of the mechanism and to get them to approach it rapidly when it operates. Most often the mechanism is operated automatically, although Ferster and Skinner (1957) suggested that an experimenter's operating it while watching the animal would be more effective.

Presumably, MT facilitates operant conditioning, but actually little published research verifies this. What has appeared supports the belief that MT facilitates shaping (Smith \& Wilkes, 1971; Smith, 1972), but the data are far from convincing (see e.g., Miller, 1976). Other research suggests that there may be no advantage to the usual successive magazine training-shaping procedure over a simultaneous combination of the two (Davenport, 1974; Smith, Borgen, Davis, \& Pace, 1971). Furthermore, judging from the literature, there is a lack of consensus on several procedural aspects. These include the number of paired presentations of the reward and the delivery stimuli, the length of time the reward remains available after delivery, and the time between operations of the reinforcer-delivery mechanism. The present investigation was concerned with the effect of reinforcer spacing on the strength of approach responses to a water dipper.

Research on the effect of varying spacing of reinforcers during MT is scant. Smith (1972) found that a variabletime (VT) schedule of $150 \mathrm{sec}$ was superior to one of 30 sec in autoshaping pigeons to keypeck; however, it is not clear whether the effect of the schedule was on the magazine-training or the shaping phase because the two phases occurred simultaneously. However, the hypothesis that MT is facilitated by increasing the spacing of the

This research was supported in part by a faculty minigrant from the State University College of Arts and Science, State University of New York, Plattsburgh, New York. We wish to thank James Miner and Linda Deering for their assistance with the subjects, and Dr. Peter Hornby for his helpful comments on the manuscript. Reprint requests should be addressed to Henry Morlock, Department of Psychology, State University College of Arts and Science, Plattsburgh, NY 12901. reinforcers seems reasonable. This should increase the extent to which the click and other stimuli from the reinforcer-delivery mechanism predict the occurrence of reinforcement (see Dickenson \& Mackintosh, 1978).

The following studies attempted to clarify the situation and to determine whether there was a practical advantage to using spaced as opposed to massed reinforcer deliveries during MT.

\section{EXPERIMENT 1}

This experiment used an extinction test to determine whether MT was more effective when the reinforcers were spaced on a VT $120 \mathrm{sec}$ schedule or on a VT $30 \mathrm{sec}$ schedule.

\section{Method}

Subjects. A group of 18 male Sprague-Dawley rats from Taconic Farms, Germantown, New York, was divided randomly into three groups of 6 . The mean age of the subjects at the beginning of their training was 115 days. They were housed individually, with Purina Rodent Laboratory Chow continuously available. The laboratory lights were on a $12 / 12$-h cycle.

Apparatus. Training and testing took place in a conditioning chamber $25 \mathrm{~cm}$ wide $\times 31 \mathrm{~cm}$ long $\times 27 \mathrm{~cm}$ high, which was enclosed in a sound-insulated chest. A .01-cc-capacity dipper provided water periodically within a circular, recessed area $3 \mathrm{~cm}$ in diameter and $1.5 \mathrm{~cm}$ above the grid floor. A photocell device detected when the subject had inserted its head $1 \mathrm{~cm}$ into the recess. Dipper operation was controlled by electromechanical units paced by a tape reader. Tapes were punched to produce two VT schedules of dipper operation: VT $30 \mathrm{sec}$ and VT $120 \mathrm{sec}$. For both tapes the standard deviations and ranges of the specific intervals used were $10 \mathrm{sec}$ and $30 \mathrm{sec}$, respectively. Operation of the dipper produced a 95-dB click as measured by a General Radio Sound Level Meter whose microphone was placed $2 \mathrm{~cm}$ in front of the water dipper recess. A constant background masking noise of $72-73 \mathrm{~dB}$ was presented through a speaker behind the front wall. Observation of the sound-level meter through a viewing port indicated that the occasional noises from the outside apparatus did not exceed the noise level of the inner environment. The chamber was lit by a 28 -volt houselight mounted at the top of the front wall. A Cramer running time meter, read to $1 / 10$ of $1 \mathrm{sec}$, provided response times (defined as the moment of dipper operation to the breaking of the beam inside the recess). A 3-cm-wide lever projected $2 \mathrm{~cm}$ into the chamber from the left side of the front wall. A metal shield was placed in front of it during magazine training and was kept in place during the extinction trials of this study. 
Procedure. The subjects were handled once for $2 \mathrm{~min}$ and then placed on a 23-h water-deprivation regimen for 5 days. The daily hour of water availability was set at the same time of day as the magazine training. On Day 5, the day of training, the subjects were given $30 \mathrm{~min}$ of free exploration of the box, and then, for two groups, the dipper was operated 60 times on either the VT $30 \mathrm{sec}$ schedule or the VT $120 \mathrm{sec}$ schedule, according to the VT schedule for the group. For the third group, the control group, dipper operation and water delivery were unpaired. Here, the empty dipper was operated by one VT $30 \mathrm{sec}$ tape, while at the same time another VT $30 \mathrm{sec}$ tape, operating independently, cued the experimenter when to silently inject a drop of water through a tube into the cup of the dipper. Excess water from the injection spilled into a receptacle below the dipper. In this way the control group received 60 dipper operations and 60 fillings of the dipper cup, independently. After their training, all groups were given 30 min of access to water in their home cages and then were deprived for another $23 \mathrm{~h}$. The following day all subjects received 30 extinction trials in which the dipper was operated without water. The experimenter recorded whether the subject approached the dipper within $5 \mathrm{sec}$ after its operation. Five sec defined the upper limit used to identify an approach response, because a slowly moving subject could take that long to walk to the dipper from the back of the box. Ten intervals of $30 \mathrm{sec}, 60 \mathrm{sec}$, and $120 \mathrm{sec}$ each composed the 30 intervals used on the tape. These were combined in a block-randomized manner.

\section{RESULTS}

The means and standard deviations of the approach responses during extinction-that is, responses with latencies of $5 \mathrm{sec}$ or less-are indicated in Table 1. Statistical analyses indicated that each of the following was significant: the main effect of schedule $[\mathrm{F}(2,15)=4.13$, $p<.05]$, the main effect of first versus second half of extinction $[\mathrm{F}(1,15)=13.81, \mathrm{p}<.01]$, and the interaction between schedule and extinction halves $[\mathrm{F}(2,15)=4.44$, $\mathrm{p}<.05]$. Analyses of the interaction indicated that the effect of schedule was significant $[F(2,15)=6 / 37, p<.01]$ in the first half of the extinction trials, but not in the second. Newman-Keuls analyses for the first half showed that both the VT $30 \mathrm{sec}$ and VT $120 \mathrm{sec}$ groups made significantly more responses during extinction than did the control group, but unfortunately for our hypothesis, the difference between the VT $120 \mathrm{sec}$ and VT $30 \mathrm{sec}$ groups was not significnt.

\section{EXPERIMENT 2}

Experiment 1 showed that both the VT $30 \mathrm{sec}$ and VT $120 \mathrm{sec}$ schedules were effective in establishing stimulus control of dipper-approach responses during MT. However, the data provided little support for the hypothesis that MT would be stronger when the spacing between

Table 1

Approach Responses to the Dipper During Extinction

\begin{tabular}{ccccc}
\hline & & \multicolumn{3}{c}{ Reinforcer Schedule } \\
\cline { 3 - 5 } & & VT 30 sec & VT 120 sec & Control \\
\hline Trials 1-15 & Mean & 6.2 & 8.3 & 2.7 \\
& SD & 3.0 & 3.6 & 1.2 \\
Trials 16-30 & Mean & 5.0 & 3.0 & 1.7 \\
& SD & 3.7 & 2.8 & 1.6 \\
\hline
\end{tabular}

reinforcers was greater. Of course, this is judging the effectiveness of MT on the basis of a single criterion and a relatively small number of observations. Further study might show the small trend in the direction of greater stimulus control for the 120 -sec schedule to be reliable. Nevertheless, given the above, we wondered whether it was efficient to use schedules as spaced as 120 -sec in shaping barpressing. In this experiment rats were given MT under either VT $30 \mathrm{sec}$ or VT $120 \mathrm{sec}$ spacing and then were exposed to a "working" lever. This design is similar to that used by Ponicki (1974), who investigated autoshaping of leverpressing in rats. We counted the numbers of responses the subjects made during the first 30 min of exposure to the lever to determine whether the difference in MT schedules made a difference in rapidity of leverpress learning.

\section{Method}

Subjects and Apparatus. A group of 24 male Sprague-Dawley-derived rats from the animal maintenance facility of the State University of New York at Plattsburgh was randomly divided into two groups of 12 subjects each. Mean age at beginning of training was 138 days. All aspects of housing and apparatus were similar to those of the first study.

Procedure. As in the first study, the subjects were given 5 days of a 23-h water-deprivation schedule before MT was carried out. However, both groups of subjects were given $30 \mathrm{~min}$ of exploration of the apparatus the day before MT. On the day of MT the subjects in one group were given 60 paired presentations of dipper and water on a VT $30 \mathrm{sec}$ schedule; the subjects in the other group were given 60 paired presentations of dipper and water on a VT $120 \mathrm{sec}$ schedule. As in the first study, the subjects were then given water, and after a 23-h deprivation period were placed in the chamber. The shield in front of the lever was removed, exposing the lever and three holes, each $1.5 \mathrm{~cm}$ in diameter, arrayed horizontally $5 \mathrm{~cm}$ above the lever. Exploration of these holes seemed to facilitate learning to leverpress. The subjects were given $30 \mathrm{~min}$ during which they could respond; each leverpress resulted in a filled water dipper. The number of leverpresses made during this time was recorded. No further MT nor any shaping was given.

\section{RESULTS}

Ten subjects from each group made 12 or more responses on the lever. The subjects on the VT $30 \mathrm{sec}$ schedule made a mean of 168.9 responses (standard deviation $=166.4$, range $=2-515$ ), whereas the subjects on the VT $120 \mathrm{sec}$ schedule made a mean of only 124.8 responses (standard deviation $=130.6$, range $=1$ 361 ). The difference between the means is in a direction opposite that which one would expect if the greater spacing of reinforcers during MT had produced a stronger MT; however, the difference is not statistically significant.

\section{DISCUSSION}

Since the subjects on the VT 30 sec schedule learned to approach the dipper and to press the lever about as well as the subjects on the VT $120 \mathrm{sec}$ schedule, we conclude that in MT it is inefficient to use schedules that have long intervals between presentations of reinforcers. This is not to say that there are no important effects of varying reinforcer spacing; simply that using wide spacing may not be worth the time it takes when the only goal is to train the subject to leverpress. Furthermore, we noted on several occasions that some subjects on the VT $120 \mathrm{sec}$ schedule became lethargic during their MT. In preliminary studies, in which 
subjects were run in the afternoon, some subjects on the 120 -sec schedule went to sleep and could not complete their MT in a single session (cf. Innis, Simmelhag-Grant, and Staddon, 1983). We eliminated sleeping by running subjects in the early morning (Experiment 1 ) or late evening (Experiment 2 ), which comprise the more active phases of their daily activity cycle.

One might wonder whether schedule-induced differences were obscured by leaving the dipper up-the reward accessible-throughout the interreinforcer interval. Certainly this would seem to "dilute" any spacing effort and to promote accidental associations between reinforcers and irrelevant cues. However, for the most part the subjects on both schedules approached the dipper and consumed all the water available quite rapidly, usually within $5 \mathrm{sec}$ by the end of training. In any case, our procedure is analogous to the situation in which food pellets are dropped into a food tray at intervals and left there until the subject finds them. Thus the results can be applied at least to this type of MT, if not to the type in which access to reinforcers is limited to a few seconds. This is the typical case in the training of pigeons, in which a food hopper is raised for 3-5 sec and then lowered out of reach.

\section{REFERENCES}

DAVENPORT, J. W. (1974). Combined autoshaping-operant (AO) training: CS-UCS interval effects in rats. Bulletin of the Psychonomic Society, 3, 383-388.
Dickenson, A., \& MaCkintosh, N. J. (1978). Classical conditioning in animals. In M. R. Rosenzweig \& L. W. Porter (Eds.), Annual Review of Psychology, 29, 587-612.

Ferster, C. B., \& SkINNER, B. F. (1957). Schedules of reinforcement. New York: Appleton-Century-Crofts.

InNis, N. K., Simmelhag-Grant, V. L., \& Staddon, J. E. R. (1983). Behavior induced by periodic food delivery: The effects of interfood interval. Journal of the Experimental Analysis of Behavior, 39, 309-322.

MiLLER, L. (1976). Acquisition of lever pressing by rats with and without magazine training. Psychological Record, 26, 355-359.

PoNICKI, E. (1974). A simple technique for auto-shaping lever pressing by the rat within a single session. Psychological Record, 24, 119-122.

SмIтн, S. G. (1972). A comparison of three procedures for automatic magazine and key-peck training in the pigeon. Psychological Record, 22, 211-216.

Smith, S. G., Borgen, L. A., Davis, W. M., \& Pace, H. B. (1971). Automatic magazine and bar-press training in the rat. Journal of the Experimental Analysis of Behavior, 15, 197-198.

SMITH, S. G., \& WilkES, W. P. (1971). An automatic method for obtaining magazine approach behavior and key pecking in the pigeon. Psychological Record, 21, 373-375.

(Manuscript received for publication July 15, 1985.) 